\section{(2) OPEN ACCESS}

\title{
Pericardial relapse of multiple myeloma
}

\author{
Lee S Jamison, ${ }^{1}$ Clifton Craig Mo, ${ }^{2}$ Mary Kwok ${ }^{3}$
}

\begin{abstract}
${ }^{1}$ Department of Internal Medicine, Fort Belvoir Community Hospital, Fort Belvoir, Virginia, USA

${ }^{2}$ Department of Medical Oncology, Dana Farber Cancer Institute, Boston, Massachusetts, USA

${ }^{3}$ Department of Hematology Oncology, Walter Reed National Military Medical Center, Bethesda, Maryland, USA
\end{abstract}

\section{Correspondence to Dr Lee S Jamison; lee.s.jamison@gmail.com}

Accepted 27 February 2020
Check for updates

(C) BMJ Publishing Group Limited 2020. Re-use permitted under CC BY-NC. No commercial re-use. See rights and permissions. Published by BMJ.

To cite: Jamison $\mathrm{LS}$, Mo CC, Kwok M. BMJ Case Rep 2020;13:e233340 doi:10.1136/bcr-2019233340

\section{SUMMARY}

In patients who experience relapse of multiple myeloma, upwards of $30 \%$ can have extramedullary disease. The presence of extramedullary multiple myeloma is typically associated with adverse cytogenetics and a poor prognosis. Organs most commonly involved include the liver, skin, central nervous system, pleural effusions, kidney, lymph nodes, and pancreas. We present the case of a 53-year-old man with IgA kappa multiple myeloma with the adverse cytogenetic findings of $t(4 ; 14)$ and $1 q 21$ gain who had achieved a stringent complete $(\mathrm{s} C \mathrm{R})$ response after initial therapy with carfilzomib, lenalidomide and dexamethasone. Stringent complete response is defined as the normalization of the free light chain ratio in the serum and an absence of clonal cells in the bone marrow in additiion to criteria needed to achieve complete response. Prior to undergoing a planned autologous stem cell transplant, this patient experienced cardiac tamponade secondary to extramedullary relapse of his multiple myeloma which was limited to the pericardium. In response, his treatment regimen was transitioned to pomalidomide, bortezomib, dexamethasone and cyclophosphamide for three cycles after which he again achieved sCR and ultimately underwent autologous stem cell transplant. Posttransplant consolidation therapy was administered in the form of pomalidomide, bortezomib and dexamethasone, followed by pomalidomide and bortezomib maintenance, which he has continued to receive for 3 years without evidence of disease progression.

\section{BACKGROUND}

Extramedullary relapse of multiple myeloma involving the pericardium is a recognised but extremely rare occurrence. In this case, the presence of pericardial disease resulted in a large pericardial effusion and tamponade physiology requiring pericardiocentesis. This reinforces the diagnostic imperative of including malignancy in the differential diagnosis of pericardial effusion in patients with multiple myeloma, in addition to the other more common etiologies such as traumatic catheter placement, infection or drug exposure. This case may also highlight a way forward for the treatment of patients with adverse cytogenetics and extramedullary relapse involving the pericardium, as a durable sCR has been maintained in our patient using a modified novel agent-based drug regimen in addition to high-dose melphalan with autologous stem cell transplant.

\section{CASE PRESENTATION}

A 53-year-old Caucasian man with a distant history of stage IA (T1aNOM0) malignant melanoma treated surgically with wide local excision presented to his primary care provider with several weeks of progressively worsening right knee and thigh pain. Plain films were obtained and notable only for degenerative changes, though an MRI acquired a year earlier demonstrated the presence of multiple meniscal tears. He was referred to orthopaedics for further evaluation, where an MRI of the right knee revealed 'new extensive soft tissue replacement of the marrow of the distal diaphysis and metaphysis of the right femur' suspicious for a malignant process. Surgical biopsy of the distal femur was consistent with a plasma cell neoplasm. No evidence of malignant melanoma was detected. A positron-emission tomography (PET) scan was performed the next day and detected the presence of wide-spread hypermetabolic lytic bone lesions (figure 1). Subsequent evaluation to include serology and bone marrow biopsy resulted in the diagnosis of Revised International Staging System (R-ISS) stage II, IgA kappa multiple myeloma with adverse cytogenetics, to include $\mathrm{t}(4 ; 14)$, gain of $1 \mathrm{q} 21$, deletion of $13 \mathrm{q}$ and trisomy 9. The bone marrow aspirate was comprised of an estimated $60 \%-70 \%$ malignant plasma cells. Serum creatinine and calcium were 0.94 and $9.0 \mathrm{mg} / \mathrm{dL}$, respectively. The patient was initiated on induction therapy with carfilzomib, lenalidomide and dexamethasone for

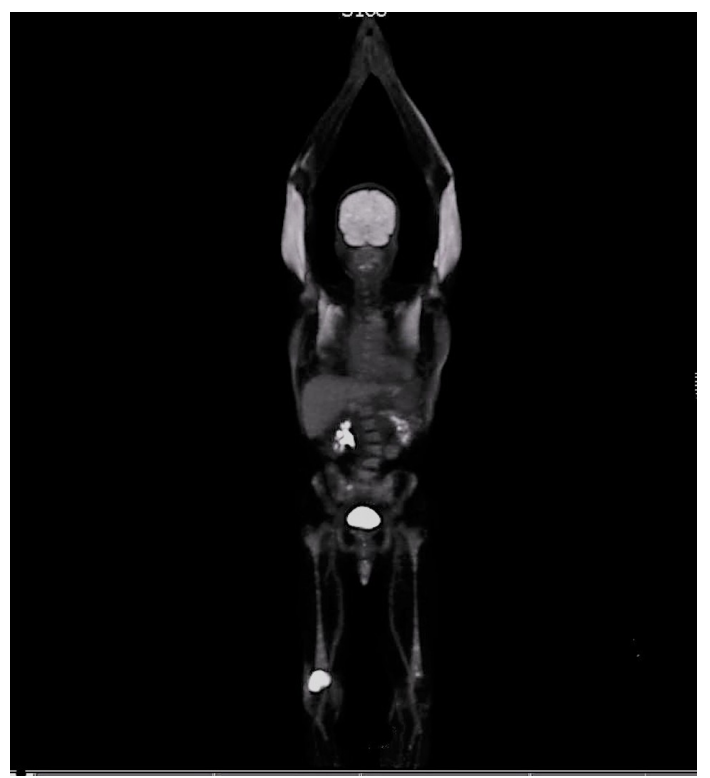

Figure 1 Positron emission tomography/computed tomography (PET/CT) at the time of diagnosis demonstrating increased metabolic activity in the left humerus, right sacrum and right femur, and too numerous to count subcentimetre lytic skeletal lesions. 
a total of five cycles prior to a planned autologous stem cell transplant. sCR was achieved after the first cycle and no complications were reported during the subsequent four cycles. The patient was admitted for stem cell mobilisation sation with granulocyte colony stimulating factor and plerixafor, resulting in the successful collection of $13.69 \times 10^{6} \mathrm{CD} 34+$ cells/kg over 2 days. However, on the evening following the second day of apheresis, the on-call physician was summoned to the bedside for acuteonset dyspnoea. Physical examination at the time of diagnosis was notable for tachycardia, elevated jugular venous pressure and a grade III/VI systolic ejection murmur at the right upper sternal border. ECG demonstrated sinus tachycardia with electrical alternans. A CT of the chest with contrast was negative for the presence of any pulmonary emboli, though it did demonstrate a large pericardial effusion. An urgent transthoracic echocardiogram was then performed, confirming the presence of moderate tamponade physiology. Shortly thereafter, the patient underwent a pericardiocentesis with removal of approximately $800 \mathrm{cc}$ of fluid. Pathologic review of the pericardial fluid confirmed the presence of malignant plasma cells with cytogenetics identical to the patient's known myeloma. Evaluation of the peripheral blood, serum protein electrophoresis (SPEP), serum light chains, repeat bone marrow biopsy and PET/CT was all unremarkable, indicating that the extramedullary relapse was isolated to the pericardium (table 1 , figure 2 ).

\section{INVESTIGATIONS}

\section{DIFFERENTIAL DIAGNOSIS}

Pericardial effusions are a relatively common finding in patients with cancer with breast and lung cancer, melanoma, lymphoma and leukaemia accounting for the majority of cases. ${ }^{1}$ In some instances, the effusion may be related to chemotherapeutic medications, colony stimulating factors and/or radiation rather than the malignancy itself. Pericardial effusions developing as a result of central venous catheter placement are rare, but have been reported. Additionally, due to the compromised immune status of patientswith cancer, they are at a greater risk of viral and bacterial infections which may affect the pericardium. Our patient's presenting complaint was dyspnoea. He was afebrile. Leukocytosis with a left shift was present. However, he had just undergone hematopoietic stem cell mobilisation with granulocyte colony stimulating factor and plerixafor. CT of the chest did not reveal any infiltrates or consolidations consistent with an infectious process. Culture of the pericardial fluid was negative, making infectious causes less likely. He did recently have an apheresis catheter inserted into his right internal jugular vein 2 days prior to onset of symptoms, but this had been performed under fluoroscopic guidance without any indication of traumatic placement. Nonetheless, the catheter was uneventfully removed 5 days later after completion of stem cell collection. Prior exposure to carfilzomib and lenalidomide is associated with the development of cardiac failure and ischaemic heart disease, but not with acute pericarditis or pericardial effusions. ${ }^{2}$ There was no prior history of any radiation therapy. Effusions occurring after administration of granulocyte colony stimulating factor are thought to result from the release of inflammatory cytokines leading to increased capillary permeability, which would not account for the presence of malignant cells. ${ }^{3}$ Pathologic review of the pericardial fluid revealed the presence of malignant plasma cells with identical cytogenetics to the patient's index malignancy. No evidence of melanoma was detected. These pathological and cytogenetical findings, in conjunction with a
Table 1 Body fluid analysis, CBC, serology and bone marrow aspirate karyotype at time of pericardial relapse

\begin{tabular}{|c|c|c|c|}
\hline \multicolumn{4}{|l|}{ Pericardial fluid } \\
\hline & Result & Units & Normal range \\
\hline Glucose & 77 & $\mathrm{mg} / \mathrm{dL}$ & \\
\hline Protein & 4.1 & $\mathrm{~g} / \mathrm{dL}$ & \\
\hline LDH & Greater than 2500 & $\mathrm{U} / \mathrm{L}$ & \\
\hline Flow cytometry & \multicolumn{3}{|c|}{$\begin{array}{l}16 \% \text { monotypic plasma cells. Positive for CD138 and } \\
\text { CD38, with kappa light chain restriction. Negative for } \\
\text { CD56, CD19, CD20, CD45 }\end{array}$} \\
\hline FISH & \multicolumn{3}{|c|}{$\begin{array}{l}\text { Gain of chromosome } 9, t(4 ; 14) \text {, and a monosomy for } \\
\text { chromosome } 13\end{array}$} \\
\hline $\begin{array}{l}\text { Aerobic and anaerobic } \\
\text { culture }\end{array}$ & \multicolumn{3}{|l|}{ No growth } \\
\hline \multicolumn{4}{|l|}{ Blood } \\
\hline & Result & Units & Normal range \\
\hline WBC & $51.5^{*}$ & $\times 10^{9} / \mathrm{L}$ & $3.6-10.6$ \\
\hline RBC & 3.27 & $\times 10^{12} / \mathrm{L}$ & $4.21-5.92$ \\
\hline $\mathrm{Hb}$ & 105 & $g / L$ & $12.8-17.7$ \\
\hline Hct & 31.8 & $\%$ & $37.5-50.9$ \\
\hline MCV & 97.4 & $\mathrm{fL}$ & $79.5-96.8$ \\
\hline $\mathrm{MCH}$ & 32.0 & $\mathrm{pg}$ & $26.2-33.1$ \\
\hline $\mathrm{MCHC}$ & 32.8 & $\mathrm{~g} / \mathrm{dL}$ & $32.6-35.0$ \\
\hline RDW & 14.6 & $\%$ & $12.0-16.2$ \\
\hline Platelets & 151 & $\mathrm{X} 10(3)$ & $162-427$ \\
\hline MPV & 6.4 & $\mathrm{fL}$ & $7.0-10.9$ \\
\hline Myelocytes & 2 & $\%$ & \\
\hline Neutrophils bands & 11 & $\%$ & $0-10$ \\
\hline Atypical lymphocytes & 1 & $\%$ & 0 \\
\hline Neutrophils segmented & 78 & $\%$ & $40-75$ \\
\hline Lymphocytes & 5 & $\%$ & $12-47$ \\
\hline Monocytes & 1 & $\%$ & $4-12$ \\
\hline Metamyelocytes & 2 & $\%$ & 0 \\
\hline LDH & 307 & $\mathrm{U} / \mathrm{L}$ & \\
\hline Protein & 5.3 & $\mathrm{~g} / \mathrm{dL}$ & \\
\hline \multicolumn{4}{|l|}{ SPEP } \\
\hline & Result & Units & Normal range \\
\hline Protein & 4.7 & $\mathrm{~g} / \mathrm{dL}$ & $6.0-8.5$ \\
\hline Albumin & 2.8 & $\mathrm{~g} / \mathrm{dL}$ & $3.2-5.6$ \\
\hline Protein monoclonal & Not observed & $\mathrm{g} / \mathrm{dL}$ & \\
\hline \multicolumn{4}{|c|}{ Kappa + lamda light chains (LCs) free with kappa/lambda ratio } \\
\hline & Results & Units & Normal range \\
\hline Ig LC kappa free & 11.04 & $\mathrm{mg} / \mathrm{L}$ & $3.30-19.40$ \\
\hline Ig LC lamda free & 11.00 & $\mathrm{mg} / \mathrm{L}$ & $5.71-26.30$ \\
\hline LC kappa/lambda & 1.0 & & $0.26-1.65$ \\
\hline \multicolumn{4}{|l|}{ Bone marrow aspirate } \\
\hline & Result & \multicolumn{2}{|c|}{ Interpretation } \\
\hline Karyotype & $46, X Y$ & \multicolumn{2}{|c|}{$\begin{array}{l}\text { No evidence of an acquired clona } \\
\text { abnormality }\end{array}$} \\
\hline
\end{tabular}

${ }^{*}$ In the setting of stem cell mobilisation.

CBC, complete blood count; FISH, fluorescence in situ hybridization; $\mathrm{Hb}$, haemoglobin; $\mathrm{Hct}$, haematocrit; LDH, lactate dehydrogenase; $M C H$, mean corpuscular haemoglobin; MCHC, mean corpuscular haemoglobin concentration; MCV, mean corpuscular volume; MPV, mean platelet volume; RBC, red blood cell count; RDW, red cell distribution width; SPEP, serum protein electrophoresis; WBC, white blood cell count.

negative infectious workup and unlikely contribution from traumatic catheter placement, anti-myeloma novel agents or colony stimulating factors confirmed the diagnosis of extramedullary relapse of his multiple myeloma. Further evaluation to include 


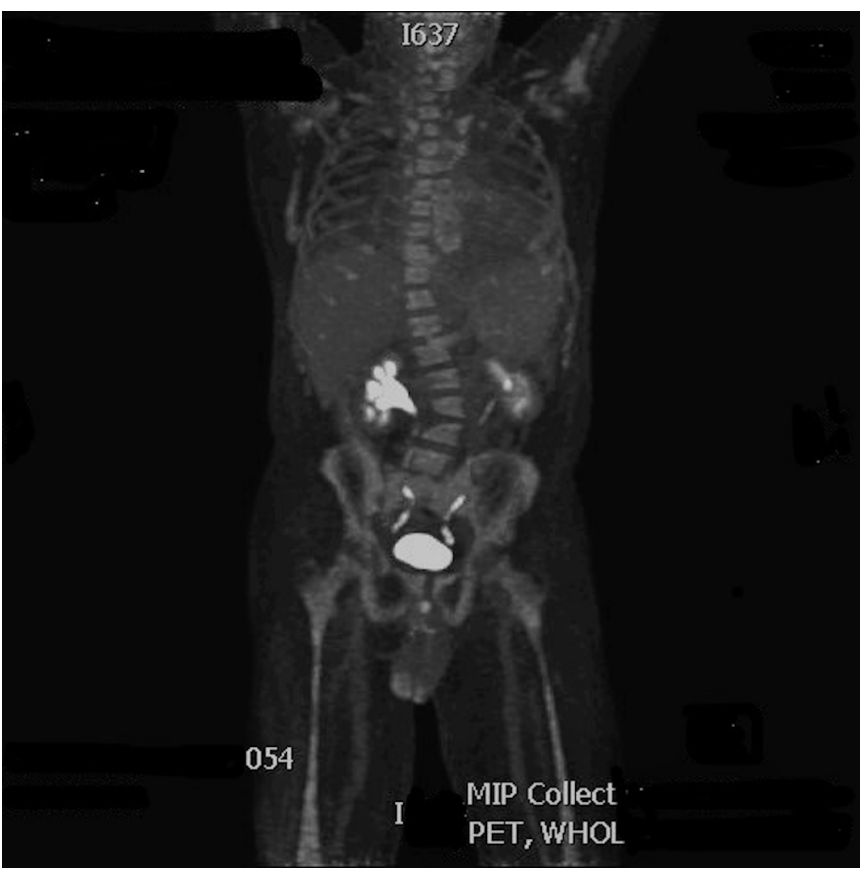

Figure 2 PET/CT at the time of isolated pericardial relapse without discrete extramedullary hypermetabolic lesions that would suggest concurrent malignancy. MIP, maximum intensity projection; WHOL, whole body scan.

review of peripheral blood, SPEP, serum free light chains, repeat bone marrow biopsy and PET scan was unremarkable, indicating that this relapse was indeed limited to the pericardium.

\section{TREATMENT}

As a result of the rapid and life-threatening nature of our patient's pericardial relapse, as well as our desire to avoid severe long-term cardiac sequelae of radiation therapy, we decided after consultation with our colleagues at Dana-Farber Cancer Institute to employ a multi-phase systemic therapy approach, starting with a four-drug regimen comprised of pomalidomide, bortezomib, dexamethasone and cyclophosphamide. At this time of this decision, novel agents such as daratumumab were not clinically available. Salvage chemotherapy with cisplatin (Platinol), doxorubicin (Adriamycin), etoposide and cyclophosphamide (PACE) based regimens were considered, but ultimately not implemented given that the relapse was isolated to the pericardium. After three cycles of treatment, without recurrence of the pericardial effusion or emergence of other evidence of disease, the patient proceeded to high dose of melphalan $(200 \mathrm{mg} /$ $\mathrm{m}^{2}$ ) with autologous stem cell rescue. Neutrophil and platelet engraftment were achieved on day 10 and 11, respectively. Two cycles of consolidation therapy with pomalidomide, bortezomib and dexamethasone were given post-transplant and then the patient was transitioned to a maintenance regimen of pomalidomide and bortezomib without corticosteroids.

\section{OUTCOME AND FOLLOW-UP}

The patient is currently on cycle 48 of maintenance therapy and remains without evidence of progression.

\section{DISCUSSION}

Due to the rarity of extramedullary relapse of multiple myeloma involving the pericardium, review of the literature is limited to several case reports (table 2) and one case review.

Onread and Boyer report a case of a 63-year-old woman with IgG kappa multiple myeloma and adverse cytogenetics, to include $\mathrm{t}(4 ; 14)$ and del $17 \mathrm{p} .{ }^{4}$ This patient initially received combination chemotherapy with bortezomib and dexamethasone. After initial relapse, she was treated with lenalidomide and bendamustine followed by an allogeneic hematopoietic stem cell transplant. Extramedullary relapse involving the pericardium occurred 2 years after transplant and the patient was subsequently treated with pomalidomide, bortezomib and dexamethasone. Unfortunately, this individual died shortly after starting the treatment.

Pan et al report a case involving a 54-year-old woman with IgG kappa multiple myeloma associated with $\mathrm{t}(4 ; 14)$, trisomy 9 and monosomy 13 . This patient was initially treated with one cycle of lenalidomide and dexamethasone in addition to radiation therapy. ${ }^{5}$ She subsequently underwent four cycles of lenalidomide, bortezomib and dexamethasone, but had progression of her osseous lesions. She was then treated with three cycles of carfilzomib, lenalidomide and dexamethasone, followed by an allogeneic stem cell transplant. Unfortunately, she suffered an extramedullary relapse involving the pericardium shortly after transplant and was transitioned to palliative care.

Zeiser et al report a case of a 55-year-old man with $\operatorname{IgA}$ kappa multiple myeloma, cytogenetics unknown, who achieved complete remission after eight cycles of dexamethasone followed by two cycles of etoposide and ifosfamide and then autologous stem cell transplant. ${ }^{6}$ Extramedullary relapse involving the pericardium occurred 7 months after transplant and the patient subsequently underwent a syngeneic allotransplant with donor hematopoietic cells from a human leucocyte antigen (HLA)identical twin. His post-transplant course was complicated by graft-versus-host disease and he remained on cyclophosphamide for an undisclosed period of time until the day of presentation to the hospital with symptomatic cardiac tamponade. The patient received 6 weeks of high-dose dexamethasone without

Table 2 Summary of case reports

\begin{tabular}{|c|c|c|c|c|c|c|c|}
\hline Patient (citation) & Age, sex & $\begin{array}{l}\text { Multiple } \\
\text { myeloma } \\
\text { subtype }\end{array}$ & Cytogenetics & $\begin{array}{l}\text { Chemotherapeutic } \\
\text { exposures }\end{array}$ & Radiation & $\begin{array}{l}\text { Pericardial relapse } \\
\text { pre or post Stem cell } \\
\text { transplant }\end{array}$ & $\begin{array}{l}\text { Survival after } \\
\text { pericardial relapse }\end{array}$ \\
\hline Patient $1^{4}$ & $63, \mathrm{~F}$ & IgG kappa & $t(4 ; 14)$ and del $17 p$ & $B, D, L$ and $B e$ & $\mathrm{~N}$ & Post & Days \\
\hline Patient $2^{5}$ & $54, \mathrm{~F}$ & IgG kappa & $\mathrm{T}(4 ; 14)$, trisomy 9 and monosomy 13 & L, D, B and C & Y & Post & Days \\
\hline Patient $3^{6}$ & $55, M$ & IgA kappa & Unreported & $\mathrm{D}, \mathrm{I}, \mathrm{E}, \mathrm{F}$ and $\mathrm{Ca}$ & $\mathrm{N}$ & Post & 6 weeks \\
\hline Patient $4^{7}$ & $73, \mathrm{~F}$ & IgG kappa & Unreported & $\mathrm{M}, \operatorname{Pr}$ and $\mathrm{D}$ & $\mathrm{N}$ & None & 9 months \\
\hline Patient $5^{7}$ & $69, \mathrm{~F}$ & IgG kappa & Unreported & $\mathrm{V}, \mathrm{A}$ and $\mathrm{D}$ & Y & None & 3 months \\
\hline Jamison, Kwok \& Mo & $53, \mathrm{M}$ & IgA kappa & $\mathrm{T}(4 ; 14)$, gain $1 \mathrm{q} 21$, del $13 q$ and trisomy 9 & $C, L, D, P, B, C y$ and $M$ & $\mathrm{~N}$ & Pre & $3+$ years, ongoing \\
\hline
\end{tabular}

A, adriamycin; B, bortezomib; Be, bendamustine; C, carfilzomib; Ca, carmustine; Cy, cyclophosphamide; D, dexamethasone; E, etoposide; F, fludarabine; I, ifosfomie; L, lenolidomide; M, melphalan; N, No; P, pomalidomide; Pr, prednisolone; V, vincristine; Y, Yes. 
Patient's perspective

'Extramedullary' was a new term for me in June 2015. I did not like the sound of it. Much worse, once I started learning more about it, I fiercely disliked its implication (a low mean survival rate) for patients with my adverse cytogenetic profile who encountered extramedullary multiple myeloma (MM) relapse. I was only 53, otherwise very healthy and had recently completed the Honolulu Marathon. The challenges from an extramedullary MM relapse would prove much more challenging than that ultimate road race.

No need for me to rehash the story: my outstanding doctors did that well in this case report. I do wish to share a 'Patient's perspective' on several aspects of this unique story in hopes of adding a human dimension to an otherwise deeply scientific matter. Physicians are (rightfully) trained to be calculating and unemotional in such circumstances. I was not, and if this commentary can add appropriate context and perspective to those who encounter such a case in the future, then I have gladly 'paid it forward' for those seeking to overcome extreme adversity in such extraordinary circumstances.

'Why?' Why the relapse? How did plasma enter my pericardium? These were the 'strategic' questions I was asking my medical team. At the 'operational' and 'tactical' level, I understood what we did in reaction to a crisis (including lifesaving pericardiocentises-which was quite a sporty procedure), but did not understand how after an unremarkable apheresis that I endured a dangerous and painful 'tamponade' (which sound like a delicious olive spread but involves all the discomfort of automobile resting on one's chest).

The bottom line is that we still do not know how plasma entered my pericardium (and $800 \mathrm{cc}$ of it at that ... about a quarter, that amount still blows me away), or why it was limited to this area. At first, that lack of direct answers to my direct questions of 'why' and 'how' were frustrating. Trained in the profession of policy and analysis, I wanted to understand the strategy of my enemy (MM), not just its operations and tactics (extramedullary pericardial effusion). On several days of reflection, research and consultation with my doctors, I was brought back to the ground truth of why cancer is the most insidious of all diseases and the nobel prize for its cure is still waiting to be awarded. The enemy's strategy remains unknown. For now, there is an uncontrollable element of MM and its manifestations. As for what was controllable, I could not have been more pleased as a patient. My medical team regrouped quickly and communicated regularly. Candid assessments were provided, even when the list of 'unknowns' was longer than the 'knowns'. autologous stem cell transplant was appropriately postponed, a return to an aggressive alternate induction therapy regime was developed and implemented, and I was afforded the opportunity for a second opinion consult outside of my primary healthcare system. I appreciated the integrity and humility of my doctors who emphasised since day one of my diagnosis that 'There were no egos here, if a second opinion was required to achieve success then we support getting one'.

Closing thoughts for other patients, but also of value to the full range of MM care givers:

Research and learn

Start with authoritative sources provided by the best in the field. Visit your hospital's research librarian to share tips on learning more about the enemy. In the Intelligence Community, we call this 'intelligence preparation of the battlespace'. I always
Patient's perspective Continued

laugh at that terminology ... only because it is true. There is an important scientific lexicon associated with cancer in general, MM specifically and extramedullary relapse in particular. Become fluent in this language so that you can engage in meaningful dialogue with your medical team and better understand MM resources available to you at your own time (and you will have plenty of it during treatment). I did and I felt that it made a positive impact on a positive outcome.

I am now in a 3+ year stringent complete response. This relapse was the second most trying time of this cancer journey. By far, number one was the initial diagnosis, during which my wife and I blew through the five stages of grief (denial, anger, bargaining, depression and acceptance) very quickly in order to get after a rapid solution.

Teamwork, tone and tenacity

You should have a strategy to overcome the unexpected, unwanted and uncertain. Employ the following three effective tools:

- Teamwork: with medical pros (doctors, nurses and administrators), office colleagues to cover your absence and family and friends to assist from small to large household chores.

- Tone: you will be emotionally stress tested: patient and spouse. It takes real effort in these new circumstances to keep your cool with each other inside the house and beyond your home with others. Work on coming up with plans to relieve tension and decrease stress.

- Tenacity: you cannot control some aspects of the cancer inside your body (but medicine helps). You can control how intensely you learn about the science of treatment, undertake physical rehabilitation and maintain a positive focus on the future.

Develop a network of cancer patient and cancer survivor colleagues

Outside of my doctors, this group brought the greatest source of information and inspiration. Some were patients with MNN, others not. All added value to understanding the fight. I chose not to attend local community cancer support groups because that is not how I best absorb new information. However, I know others who did and were pleased with their results. I focused on phone calls and emails with friends, or friends of friends who were introduced to me and willing to share their stories of triumph over tragedy. There were no extramedullary patients for me to consult with. I offer my availability to anyone, anytime that encounters this situation.

Plan on disrupted timelines and unexpected events

As a senior military officer, I was used to crisp timelines and planned outcomes on neat schedules. Even with previous medical experiences such as broken bones, infections and even a medical evacuation from an Afghanistan combat zone, treatment rhythms seemed predictable. That certainly is not the case with an MM extramedullary relapse. So gear your thinking to flexibility and change ... that takes some getting used to.

Take time off work ... lots

Too much effort back in the office too soon is a recipe for a slower recovery. There is certainly a therapeutic value in seeing colleagues in one's workplace and contributing to a common mission, but moderation early on is key. Oh, and take a nap whenever you think it is necessary. During cancer recovery, sleep 
Patient's perspective Continued

is essential for recovery; for patientswith cancer, it is not a sign of professional weakness.

Your actions under adversity will either:

1. inspire others to follow your lead or

2. inspire others to avoid acting the same way.

Both will leave a lasting impression ... choose wisely.

You are not damaged goods

The setbacks, sustained feelings of illness and a struggle to know "When will I heal?" will tempt one to believe they're irreparably broken. A good friend emphasised to me when I shared such concerns, "You are not damaged goods." Temporarily ill and under repair; yes ... permanently broken; no. The list of MM survivors and what they've accomplished with their families and in their professions as a result of continually improved treatment outcomes refutes that we are damaged goods ... I am convinced that patients with MM, and even those who endure an extra medullary relapse, can emerge improved in many ways.

Live your life well.

That is the best revenge over cancer. Be it known that patients with extramedullary MM relapse can triumph over tragedy!

recurrence of the pericardial effusion, but eventually succumbed to complications from pneumonia.

A 2005 case review by Abelman, Virchis and Yong discusses 22 instances where extramedullary relapse of myeloma involved the pericardium. ${ }^{7}$ Multiple myeloma subtype and genetics were highly variable, as were the treatment regimens which involved a combination of systemic therapy, stem cell transplant, intrapericardial chemotherapy and radiation. Median survival after relapse was 13.5 weeks.

Our case is unique in several aspects in comparison to other reported incidences. First, our patient experienced

Learning points

- Extramedullary relapse of multiple myeloma involving the pericardium is extremely rare, though must remain on the differential for any patient with a history of multiple myeloma presenting with signs and symptoms consistent with pericardial effusion and tamponade. Pericardial fluid collected during pericardiocentesis should always be sent for cytology.

- Though post-transplant is more common, extramedullary relapse to include involvement of the pericardium can occur pre-transplant.

- In general, the prognosis is very poor for patients presenting with extramedullary relapse involving the pericardium. However, in eligible patients, the combination of pomalidomide, bortezomib, dexamethasone and cyclophosphamide in addition to autologous stem cell transplant, consolidation chemotherapy and a maintenance regimen of pomalidomide and bortezomib may prove to be an effective treatment strategy. extramedullary relapse prior to versus after autologous stem cell transplant. Second, his relapse was isolated to the pericardium without other evidence of intramedullary or extramedullary disease. Third, our patient is the first in the literature to receive four-agent consolidation therapy after autotransplant followed by indefinite dual-agent (immunomodulator imide and proteasome inhibitor) maintenance. Lastly, our patient has experienced a deep and durable response to this treatment regimen for over 3 years, making him the longest surviving patient, to the best of our knowledge, after suffering a pericardial relapse of multiple myeloma. Although we cannot know with certainty, it is possible that one or more aspects of our unique therapeutic approach, such as the use of dual-agent maintenance therapy after autotransplant, may be responsible for this uniquely positive outcome.

The one constant among all of these cases is the heterogeneity of the treatment regimens given. This likely reflects both the rare nature of this presentation as well as the rapidly evolving treatment landscape of multiple myeloma and it highlights the difficulty in constructing any guideline-directed standard of care for this small group of patients. However, given the excellent outcome our patient has experienced, it would not be unreasonable to consider our approach for similar patients with relapsed/refractory myeloma involving the pericardium.

Acknowledgements I would like to acknowledge Drs Mary Kwok and Clifton Mo in addition to our patient, for providing their perspective.

Contributors LSJ is responsible for performing the literature search, compiling the relevant data and writing the case report. He will also serve as a guarantor. MK and CCM were directly involved in patient care during this individual's treatment in addition to providing editorial supervision to LSJ while composing the case report.

Funding The authors have not declared a specific grant for this research from any funding agency in the public, commercial or not-for-profit sectors.

Competing interests None declared.

Patient consent for publication Obtained.

Provenance and peer review Not commissioned; externally peer reviewed.

Open access This is an open access article distributed in accordance with the Creative Commons Attribution Non Commercial (CC BY-NC 4.0) license, which permits others to distribute, remix, adapt, build upon this work non-commercially, and license their derivative works on different terms, provided the original work is properly cited and the use is non-commercial. See: http://creativecommons.org/ licenses/by-nc/4.0/.

\section{REFERENCES}

1 Besse L, Sedlarikova L, Greslikova H, et al. Cytogenetics in multiple myeloma patients progressing into extramedullary disease. Eur J Haematol 2016;97:93-100.

2 Stewart AK, Rajkumar SV, Dimopoulos MA, et al. Carfilzomib, lenalidomide, and dexamethasone for relapsed multiple myeloma. N Engl J Med 2015;372:142-52.

3 de Azevedo AM, Goldberg Tabak D. Life-Threatening capillary leak syndrome after G-CSF mobilization and collection of peripheral blood progenitor cells for allogeneic transplantation. Bone Marrow Transplant 2001;28:311-2.

4 Onraed J, Boyer T. Relapse of multiple myeloma presenting as pericardial effusion. Blood 2019;133:619.

5 Pan J, Chen J, Filicko J, et al. Relapsed multiple myeloma presenting as intracranial plasmacytoma and malignant pericardial effusion following recent allogeneic stem cell transplantation. Case Rep Oncol 2017;10:582-7.

6 Zeiser R, Hackanson B, Bley TA, et al. Unusual cases in multiple myeloma and a dramatic response in metastatic lung cancer. J Clin Oncol 2005;23:230-1.

7 Abelman W, Virchis A, Yong K. Extramedullary myeloma representing as a pericardial effusion with tamponade: two case reports and a further review of 19 cases in the literature. Leuk Lymphoma 2005;46:137-42. 
Copyright 2020 BMJ Publishing Group. All rights reserved. For permission to reuse any of this content visit https://www.bmj.com/company/products-services/rights-and-licensing/permissions/

BMJ Case Report Fellows may re-use this article for personal use and teaching without any further permission.

Become a Fellow of BMJ Case Reports today and you can:

- Submit as many cases as you like

- Enjoy fast sympathetic peer review and rapid publication of accepted articles

Access all the published articles

- Re-use any of the published material for personal use and teaching without further permission

Customer Service

If you have any further queries about your subscription, please contact our customer services team on +44 (0) 2071111105 or via email at support@bmj.com.

Visit casereports.bmj.com for more articles like this and to become a Fellow 